\title{
Evaluation System at School Level in Nepal: Major Pitfalls and Considerations
}

\author{
Yadu Prasad Gyawali \\ Mid-Western University, Surkhet
}

\begin{abstract}
This paper aims to explore the pitfalls of the current evaluation system at the school level in Nepal focusing on the major consequences of educational practices as the output of the evaluation system. Although the provisions of formative assessment tools such as portfolio management and project work were included in the curriculum framework and policy documents, the evaluation process was based on a theoretical basis. Similarly, the judgmental written examination for assessing theoretical aspects and Continuous Assessment System (CAS) with backward-looking nature were involved in the evaluation process. The paper suggests to the educational stakeholders for the practical application and evaluation of soft-skills associated methods such as communication, creativity, cooperation and collaboration of basic and secondary students to promote formative evaluation and the curriculum concept of 'assessment for learning in Nepal.
\end{abstract}

Keywords: written examination, assessment of learning, continuous assessment system, equity, soft skills, learning facilitation

\section{INTRODUCTION}

Education is the key to unlock the individual and collective needs and expectations associated with the theoretical and skill-based indicators for transforming learning situations. Teaching and learning activities and the evaluation system are interrelated to provide guidelines for achieving and redefining the educational goals as suggested in the curriculum. Likewise, the evaluation system at the school level has a greater degree of significance to measure the level of learning achievement and further planning.

MOEST (2019) advocates equity and justice for the prosperity and happiness for transforming socio-economic status through skill and quality-based practical education system in Nepal. Similarly, MOE (2016) directs on the implementation of a result-based assessment system for effective learning facilitation and encourages learners for life-skill and soft-skill-based productive learning at the school level. NPC (2020) on the other hand, relates education to employment as skill-based and vocational education might contribute to quality education with the innovative use of educational resources.

Similarly, CDC (2020) explains that the Evaluation system incorporates the assessment of learners' achievements in terms of students ' scores, behavior and contextual adaptation. However, the existing evaluation system has some practical limitations in 
assessing learning achievements. For example, CDC (2020) indicates that the current evaluation system cannot establish the relationship with learning facilitation which has created practical gaps while implementing the Continuous Assessment System(CAS) in the basic level of school education.

Despite, the provisions of formative assessment in the curriculum framework and policy documents, the evaluation procedure depends on the written examinations in terminal and unitbased. MOE (2016) has proposed formative and summative assessment at the school level such as the provision of CAS up to class seven and several indicators of summative evaluation from class eight to 12. Baral et al. (2020) assert that although teachers, students, and the education system favor the traditional teaching and evaluation procedure, there is the need for alternative modes of evaluation emphasizing the paradigm shift in the evaluation system which can assess students' behavior, creativity, critical thinking, soft-skills, and life-skills to make learners independent in their practical life. The evaluation system in school education in Nepal is largely guided by theoretical and textbook-based instruction, written examination-oriented evaluation and assessment of learning instead of assessment for learning, as a result, students' low creativity, lack of critical thinking and collaboration, rote learning, dropouts, and challenges in learning achievement stands as the major pitfalls. Therefore, the study aims to explore the pitfalls of the evaluation system at the school level in the context of Nepal concerning the available policies and other documents addressing the practices of an evaluation system. Similarly, it is necessary to identify and suggest the pitfalls of the evaluation system to intervene in new paradigms of evaluating learning outcomes.

\section{METHOD}

The present work is based on content analysis where the literatures from the different contexts such as the context of developed countries, developing countries and the local contexts were reviewed and presented in the study. The overall evaluation system of the school level was reviewed with the help of the policy documents of the Ministry of Education, Human Resource Development Center, Curriculum Development Centre, Educational Policy of Nepal, legal documents, and recent researches done by the scholars about Nepal. Following the idea of (Castleberry \& Nolen, 2018) key issues were developed in different themes and discussed relating to the rationale and the purpose of the study.

\section{DISCUSSION}

The paper aims to explore the pitfalls of the current evaluation system at School Level (i.e. .from Grade one to Grade 12) in Nepal based on the documentary analysis available in the context of Nepal. The evaluation system provides a guideline to replan the instructional activities as per the learners' level of achievement and reflection. These pitfalls which are discussed in the section are also the key issues derived from the literatures of different contexts and can suggest alternative ways of evaluation as the paradigm shift in the education system of Nepal. 


\section{The Theoretical Aspect of Evaluation}

The current evaluation system believes in the theoretical aspect in the sense that the system demands the development of the knowledge aspect of the learners. If a learner can read, write whatever is delivered by the teacher in the classroom is supposed as an intelligent student. Koirala (2019) argued that besides the theoretical part, no kind of alternative evaluation system is in practice in Nepal, and the policy level organizations bear the primary role to introduce timely examination system for example converting SLC to SEE cannot be the example of the transformation, as per the transformative concern open question system need to be presented while students can develop creativity and inquiry behaviors. Furthermore, the placement specification needs to be defined based on the secured grade by the students.

Khaniya et al. (2018) stressed that practicality needed to be in prime consideration while administering the assessment. The knowledge aspect is relevant to drive the move to a specific direction where the learner can perform their behaviors and fulfill their responsibility as per the situation. On the contrary, Rajbhandari and Wilmut (2000) claimed that the theoretical aspect is considered to be the foundation of all practical activities in which students can prepare themselves confident and accountable. For example, Wiliam (2011) illustrated classroom dialogue and innovative practices as the outcome of the theoretical basis from which learners could shape creativity and practicality in learning. Conklin (2005) stated that the theoretical aspects of the evaluation system focus on the cognitive domain only. The learners need to achieve cognitive, affective, and psychomotor domains of educational objectives as the learning outcomes (Anderson \& Bloom, 2001).

Therefore, the theoretical aspect of the evaluation system might develop knowledge for the learners; however, the practical or creative aspects can foster responsibility, self-reliance, autonomy, communication, collaboration, and relevant soft skills to realize the value of education. Similarly, the theoretical nature of the evaluation system has been affecting the provision to assess the soft skills as the students need to know the content given in the textbook

\section{Written Examination Based Evaluation System}

One of the major pitfalls of the current evaluation system at the secondary level in Nepal is written examination-based evaluation because it only focuses on students' memorization of content and scoring. The system allows students to answer questions instead of developing problem-solving and question-posing abilities. Therefore, students seem dependent on old questions, notes, and paper guides to develop cognitive ability. Khaniya et al. (2018) argued that the school-based assessment system got overlapped by the written examination and students need to seek the right answer to the particular questions in a specific time to achieve the normreferenced score for the placement to another level. Similarly, Gardner (2011) identified that students had different kinds of intelligence, such as logical, verbal-linguistics, interpersonal, intrapersonal, visual, musical, naturalist and kinesthetic and periodic written examination compelled to write the things that they memorized but could not evaluate learners' level of 
intelligence. Likewise, Bayrak and Ecerkale (2020) argued that unclear and long questions in the examination made the students worry about addressing the problem in the right way as the students only intended to secure marks.

On the other hand, MOEST (2019) claimed on the skill-based evaluation procedure following the educational taxonomy of Bloom where students cognitive, affective and psychomotor domain-based questions are asked to measure the behaviors of learners. Similarly, Baral et al. (2020) argued that examinations made the learners conscious of the content and their position.

Singh (2017) reported that the Finnish education system focused on the child's individuality and students below the age of 16 do not sit for the examinations of the national level. The lesson from the Finnish evaluation system needs to incorporate in school education in Nepal to address the communication, creativity, critical thinking ability and collaboration among learners. Therefore, the written examination system might have limitations to develop skills in problem-solving and address the ability of learners which they want to build and develop for their career.

\section{Continuous Assessment System (CAS) and Learning Facilitation}

The inequitable relationship of the Continuous Assessment System (CAS) and learning facilitation makes the evaluation system difficult because the learning facilitation strategy and the nature of the CAS have not been supported for the productive learning outcome mentioned in the curriculum. CAS is recognized as the tool of formative evaluation which demands regular activities of students based on the learning situation with remedies and supervision from the teachers. In the context of Nepal, CAS is implemented from class one to class seven. The mutual relation between teaching-learning activities and the evaluation process had been discussed for the effective implementation and evaluation system beyond teaching-learning strategies could not determine the expected learning outcome determined by the curriculum (Faubert, 2009; Rajbhandari \& Wilmut, 2000). Moreover, CDC (2020) provisioned the indicators to assess learning achievements regarding self-reference based evaluation system where students could know their level of learning and position of the social transformation, even the traditional mental schema of examination was in the midpoint of the institutions as well as the practitioners and there seem some practical gaps in implementation.

On the other hand, CDC (2019) claimed that CAS helped to reveal innateness and softskills of learners. For example, MOE (2016) illustrated the procedures for implementing the learning facilitation, such as individualized instruction, problem-solving, group or peer work, field-based teaching-learning strategies, and remedial teaching concerning the evaluation system through CAS.

Neupane (2019) highlighted that teachers' attitude and parental support are essential to implement the teaching and evaluation procedure while CAS expected individualized instruction 
to the students of different levels of the same class, but the classroom size had not been supporting it. The government and different NGOs and INGOs have been contributing to the effective implementation of learning facilitation and CAS; however, the size of the classroom, lack of teaching-learning materials, gap between theory and practice in the curriculum is the causes for the inequitable relationship of Continuous assessment system (CAS) and learning facilitation.

\section{Assessment of Learning versus Assessment for Learning}

Assessment of learning is another drawback of the evaluation system because it emphasizes the comparison of the achievement based on the learned things in the past. It is the decision-making assessment system in which students do not have further opportunities to improve from the feedback of the instructor. Assessment of learning is the traditional way of evaluating the learners as suggested by (Anastasiou \& Papagianni, 2020). It pursued the accountability of the test from the perspectives of placement by which the students can be ranked as per their score without assessing the real world view. In the context of Singapore Wood (2018) reported concerning 2022 Skills Outlook that content-based evaluation system created psychological burden and students lost their leadership skills and creativity, as a result, students could not plan their future.

On the other hand, the achievement of learning outcomes could be measured from the assessment of the learning model of the evaluation system and it can suggest to the policymakers for the improvement of the curricular goals. Baral et al. (2020) claimed that the students' achievement was associated with the content they learned in the instructional practices and that needs to be put in the provincial and nationwide indicators which are possible by assessing the content they learned throughout the academic year. However, Bayrak and Ecerkale (2020) justified that assessment of learning allowed the judgmental role of the teachers based on the past learning, as a result, innovative practices, classroom interaction, group work and remedial instruction did not take place.

Therefore, Assessment of learning is judgmental and does not suggest improvement in the learnability of the learners. Moreover, it is essential for the placement to another level while the evaluation system needs to consider the forward-looking, improvement based, remedial, interactive and student activity-oriented criteria from which learners may involve themselves in several opportunities such as project work, field visit, critical thinking, collaboration among group and teachers.

\section{CONCLUSION}

The evaluation system suggested by CDC $(2009,2012,2014,2019)$ is mostly theoretical, descriptive and also practical. From the content analysis, it was found that the examination system encouraged learners to gain and recall the information instead of developing comprehension and practice the information with the view of real-world application. 
Additionally, the current system has prepared the learners for the standardized tests of academic, provincial and national levels. The major gap was found to the practicality of the assessment system with the lack of resources, limited and theory-based training to the instructors, the traditional concept of assessment criteria and the examination based learnability of the learners on ground as a result, improvement-based evaluation is outreach; however, the policy suggests evaluating the learners based on their cognitive framework, regular activities, and soft-skills they obtained as referred to the level of the learners. As a teacher trainer, I have experienced from different training that most of the teachers are not found conscious of the use of curriculum and suggested activities as they have the mindset of teaching in the classroom and taking the examination for placement. The pitfalls might discourage learners' creativity, collaboration, cooperation and communication as a result, the learners are motivated to rote learning and learning for examination purposes only.

To explore the major pitfalls of the current evaluation system in school level education in Nepal different related and relevant literatures suggested that the major pitfalls which have been framing the learning context based on the written examination, theoretical consideration and backward-looking approaches focusing to the remembering, restoring and recalling the information. Therefore, the pitfalls are the suggestive remarks to the policymakers and practitioners to transform the evaluation system at the school level in Nepal and the students can explore the field of their interest learn the life-skills and soft-skills as per societal need, which can lead to the innovation for the curricular and other relevant areas. Furthermore, the current evaluation system might be one of the causes of student' dropout and research activities need to be expanded in the area since limited researches were found in evaluation system related fields in Nepal.

\section{REFERENCES}

Anastasiou, S., \& Papagianni, A. (2020). Parents', teachers' and principals' views on parental involvement in secondary education schools in Greece [Reports - Research]. 10.

Anderson, L. W., \& Bloom, B. S. (2001). A taxonomy for learning, teaching, and assessing: A revision of Bloom's taxonomy of educational objectives. Longman.

Baral, K., Luitel, B., \& Tiwari, R. (2020). SEE, a tool to evaluate secondary education [Interview]. Gorkhapatra Corporation. http://www.therisingnepal.org.np/news/32803

Bayrak, Ö., \& Ecerkale, N. (2020). The evaluation of secondary school students' attitudes towards social values in terms of gender [Reports - Research]. 8(1), 1-5.

Castleberry, A., \& Nolen, A. (2018). Thematic analysis of qualitative research data: Is it as easy as it sounds? Currents in Pharmacy Teaching and Learning, 10(6), 807-815.

CDC. (2009). Primary education grade 4-5. Sanothimi, Bhaktapur: Curriculum Development Centre, Nepal Retrieved from http://nepaknol.org.np/cdc/elibrary/pages/view.php?ref=64\&k=\#

CDC. (2012). Basic curriculum Class 6-8. Sanothimi Bhaktapur: Curriculum Development Centre, Nepal Retrieved from http://nepaknol.org.np/cdc/elibrary/pages/view.php?ref=382\&k=\# 
CDC. (2014). Secondary education curriculum class 9-10 part one. Sanothimi, Bhaktapur:

Curriculum Development centre, Nepal Retrieved from

http://nepaknol.org.np/cdc/elibrary/pages/view.php?ref=567\&k=\#

CDC. (2019). Basic level (Grade 1-3)curriculum. Sanothimi, Bhaktapur Curriculum

Development Centre, Nepal Retrieved from

http://nepaknol.org.np/cdc/elibrary/pages/view.php?ref=2457\&k=\#

CDC. (2020). National curriculum framework of school education-2076. Sanothimi Bhaktapur

Curriculum Development centre, Nepal Retrieved from

http://nepaknol.org.np/cdc/elibrary/pages/view.php?ref=2451\&k=\#

Conklin, J. (2005). A taxonomy for learning, teaching, and assessing: A revision of Bloom's

taxonomy of educational objectives complete edition. Educational Horizons, 83(3), 154-

159. http://www.jstor.org/stable/42926529

Faubert, V. (2009). School evaluation: Current practices in OECD countries and a literature review.

Gardner, H. (2011). Frames of mind: The theory of multiple intelligences. Hachette Uk.

Khaniya, T. R., Parajuli, T. R., \& Nakarmi, S. S. (2018). Background study: Curriculum, textbooks, and student assessment and evaluation 2015 (1156). M. o. E. Nepal.

http://nepaknol.org.np/cdc/elibrary/pages/view.php?ref=1156\&k=\#

Koirala, B. N. (2019). Education system and perspectives: SEE [Interview]. Kathmandu; AP1

HD. https://www.youtube.com/watch?v=F4361JAggjU

MOE. (2016). School sector development plan 2016-2023. Kathmandu Government of Nepal,

Ministry of Education Retrieved from

http://doe.gov.np/assets/uploads/files/3bee63bb9c50761bb8c97e2cc75b85b2.pdf

MOEST. (2019). National education policy-2076. Kathmandu Ministry of Education, Science and Teachnology Retrieved from

http://moe.gov.np/assets/uploads/files/Education_Policy.pdf

Neupane, D. (2019, May 2). Continuous assessment system: From paper to pedagogy. The

Himalayan. https:/thehimalayantimes.com/opinion/continuous-assessment-system-frompaper-to-pedagogy/

NPC. (2020). Fitfeenth plan(FY 2076/77-2080/81). Kathmandu Nepal Government, National

Planning Council Retrieved from

https://www.npc.gov.np/images/category/15th_Plan_Final1.pdf

Rajbhandari, P., \& Wilmut, J. (2000). Assessment in Nepal. Assessment in Education:

Principles, Policy \& Practice, 7(2), 255-269.

Singh, A. (2017). No homework, no board exams for children in Finland; A cue for India NDTV. https://www.ndtv.com/education/no-homework-no-board-exams-for-children-in-finlanda-cue-for-india-1743825

Wiliam, D. (2011). What is assessment for learning? Studies in educational evaluation, 37(1), 3-14.

Wood, J. (2018). Children in Singapore will no longer be ranked by exam results. Here's why. https://www.weforum.org/agenda/2018/10/singapore-has-abolished-school-examrankings-here-s-why/\# 